\title{
Comprehensive mobile crane control and safety system
}

\author{
Red'kin A.V. \\ Polytechnic Institute \\ Tula State University \\ Tula, Russia \\ ra171171@yandex.ru
}

Sorokin P.A.

dept. of Transport Engineering and Control Systems

Russian University of Transport

Moscow, Russia

pavalsor@yandex.ru

\author{
Trushin N.N. \\ Polytechnic Institute \\ Tula State University \\ Tula, Russia \\ trunikolaj@yandex.ru
}

Grinchar N.G.

dept. of Transport Engineering and Control Systems

Russian University of Transport

Moscow, Russia

grinchar@mail.ru

\begin{abstract}
The study deals with the integration of stability control systems for mobile cranes and hydraulic drives control systems when lifting operations include load-lifting path and crane position adjustments. The system's general flowchart and algorithm are presented. Crane tip-over stability margin estimation methods and their possible implementations are proposed: by center of mass position monitoring and measuring the velocity of pressure change in the outriggers hydraulic cylinders.
\end{abstract}

Keywords - load-lifting machines; control; safety; stability; monitoring.

\section{INTRODUCTION}

Today mobile crane automation is a required prerequisite for improving the crane productivity, safety, reliability, and energy efficiency [1-6]. The primary lifting and handling automated control objectives are workflow optimization, precise load positioning, reducing load oscillations while the crane stability conditions are met [7-12]. To achieve these objectives, an integrated safety system shall be in place. Such system consists of a CPU crane rated capacity limiter, travel limiters, equipment position and status monitoring, and a drive control system.

Currently the commonly used systems ensuring crane stability in operation are CPU rated capacity limiters that only monitor the crane position and do not interfere with the controls until a critical situation occurs. Extra dynamic loads caused by abrupt crane drive halts may lead to the wire rope oscillations, drastic overturning moment rise, and subsequent stability loss.

The patent search has revealed that there are works in progress related to the control and protection system integration and functionality expansion. The method and apparatus proposed in [10] partially damp the oscillations and limit startup/break dynamic loads (also caused by the safety system tripping) through monitoring the inertia values, velocities, accelerations and proactive travel limitation. The control device [11] can change the max capacity smoothly or in a step-like manner to match the loading period, mode, or phase. As a load is lifted, it is possible to specify the max load capacity in the crane azimuth angle rang. The max load value is then preserved and changes as the azimuth angle is changed. The system [12] controls the hydraulic directional valves depending on a comparison of the preset and actual boom extension and hook lift velocities, on the crane operation limits and the possibility of safe simultaneous crane movements.

\section{GENERAL CONTROL SYSTEM FLOWCHART}

There are two ways for the crane cycle optimization: load path optimization [13-19], and hydraulic motor drive velocity optimization [20-26]. Transient accelera-tion/deceleration processes are highly important for the emergence of oscillations and high dynamic overloads. It is even more so for complicated load paths and fre-quent velocity variations. So, a control system shall maintain optimal performance and limit the total load (load and boom equipment weight, dynamic processes, wind load, etc.) to ensure stability.

The comprehensive system development objective is accident prevention without deactivating the crane drives through using optimal control algorithms for each drive considering the drive contribution to the load han-dling safety.

To reach the objective, we should develop a drive con-trol system that performs the following functions:

1. Estimating max crane component velocities, accelerations (and the drive forces and torques) at every moment.

2. Generating control signals (see Item 1) to follow a predefined load path at an optimal velocity.

3. Managing feedback to monitor the crane's correct response to control actions. 
Fig. 1 shows a general flowchart of such system.

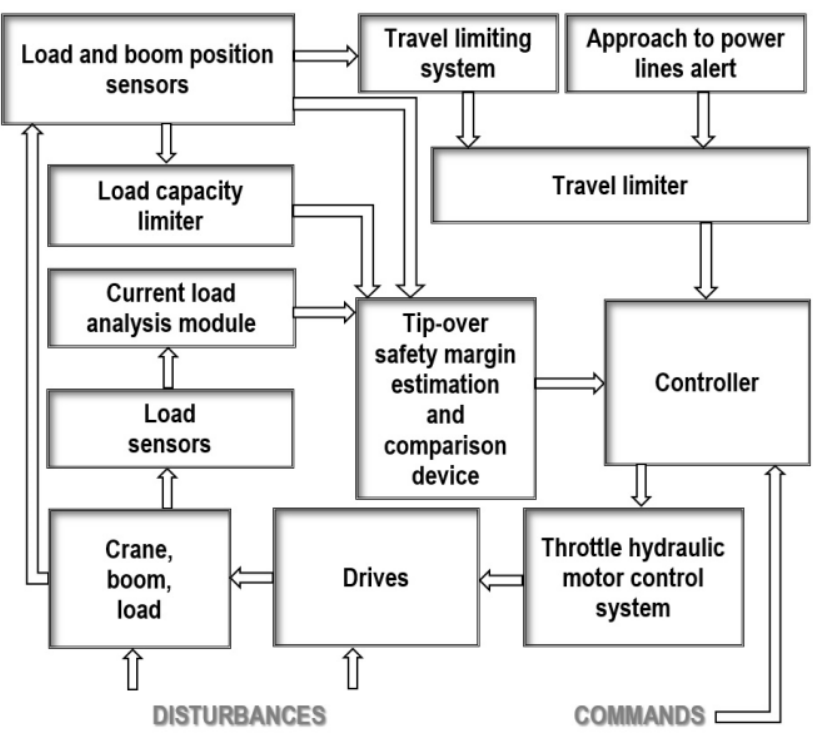

Fig. 1. Mobile crane control and protection system. General flowchart.

The crane drives have proportional control. Velocity, travel length, hydraulic motor torque (for the load lifting and rotation drives) or a hydraulic cylinder force (for the boom lift/extension drives) are controlled with throttle solenoid directional control valves that have variable hydraulic resistance and managed by a controller. In this way, a load is carried along a specified path and at a specified velocity set with the control commands.

A monitoring system tracks the position of the crane components and the load. The system comprises of azimuth angle $\alpha$, boom length $l$ and pitch $\varphi$ sensors, a wire rope length sensor, secondary transducers, and data links. Besides, there may be optional base support to horizontal angle $\gamma$ sensor and wind speed indicators to assess the wind load. The output signals are sent to the load capacity limiter, travel limiter, and the tip-over safety margin estimation and comparison device. Under the implemented mathematical model, the load capacity limiter estimates the $P_{A D D}$ values for the current position of the crane components.

The travel limiter receives the sensor signals and analyze the current load coordinates, velocity, and their direction, the shortest distance between the load and the safe load path area perimeter (in orthogonal or polar coordinates) and the velocity of approach to the perimeter. Based on these data, while monitoring a power line approach alert, the travel limiter generates path and velocity adjustments.

Various sets of both direct $[10,11]$ and indirect $[27,28]$ sensors can be used to determine the current load $F_{L}$. Respectively, the tip-over safety margin estimation and comparison device can handle either the $P_{A D D}$ and $F_{L}$ directly, or related values (center of mass to tip-over distance, see [9].) The positional sensor signals are also processed in order to estimate the tip-over safety margins for each drive control channel.
The controller uses the available information and control inputs to generate signals to the hydraulic motor throttle control system (individually in each channel.) The throttle velocity control works as follows: a portion of the pumpsupplied fluid is directed to a drain line and do not perform any work. Depending on the current max capacity setting the fluid pressure in a hydraulic motor limits its driving torque. The settings are so that the drive has a specified response time and acceptable phase shifts that define the dynamic properties of the control loop.

Disturbances are detected through the crane response to then (changes in position, load increase), or directly by the sensors. The load/position sensors make up feedback loops. Accordingly, we have a deviation control or a combined (deviation and disturbance control) follow-up system.

So, a system based on this concept (Fig. 1) enables consistent drive operation in terms of tip-over prevention and safe load paths. It virtually excludes any emergency situations without stopping the drives and halting the hoisting operation. The performance and energy efficiency are optimized with automated crane drive velocity and power management.

\section{CENTER OF MASS POSITION MONITORING FOR STABILITY CONTROL}

The proposed control approach includes the above-listed and the following actions:

1. Generating preliminary travel limit signals based on the overload/travel limit analysis, and also on the estimated distance correction calculated for a given load oscillation period.

2. Estimating the equipment inertia values, actual velocities and accelerations as the drives are started and stopped (based on the crane component position sensor signals) and determining the drive on/off timing for automated pulse control managed by the hanging load oscillation period and phase.

3. Logical data processing, drive on/off signal multiplexing and sending the signals to amplifiers that actually activate the drives.

The equation is used to estimate the current overturning moment. It is compared to the acceptable value, and the optimal boom length, load hanging height, velocities and accelerations for subsequent motions. These values are displayed on the operator panel. If the current overturning moment exceed the threshold value, the monitoring system automatically smoothly decreases the velocity to enable the operator intervention, e.g. changing the load height, velocity, acceleration, or boom length.

To monitor a stable crane position we propose a stability detection method. It monitors the direction of the resultant of all forces applied to the crane (or to the center of mass projections) with reference to the mobile crane base perimeter. The method is based on the following assumptions: 
1. To ensure a free-standing crane stability, a requirement is that the vertical resultant of the support pressure shall be within the base perimeter.

2. A stability factor is a crane stability indicator. The factor depends on the distance between the resultant fulcrum and the base perimeter.

The crane stability factor is a ratio of the base perimeter size $\left(l_{X}, l_{Y}\right.$, Fig. 2$)$ to the distance between the resultant fulcrum (or center of mass) $\mathrm{C}$ to the most remote base perimeter point:

$$
k=2 l /\left(l+b^{\prime}\right) \geq 1.2 .
$$

The controlled parameters are the center of mass projection coordinates. It can be shown that the stability factor maximum $(k=2)$ is at $C_{x}=0\left(C_{Y}=0\right)$, while the minimum ( $k$ $=1.2)$ is at $C_{X}=\left(l_{X}-0.6 l_{X}\right) / 0.6,\left(C_{Y}=\left(l_{Y}-0.6 l_{Y}\right) / 0.6\right)$. If the center of mass projection $C$ is within the area 1 , the mobile crane is stable.

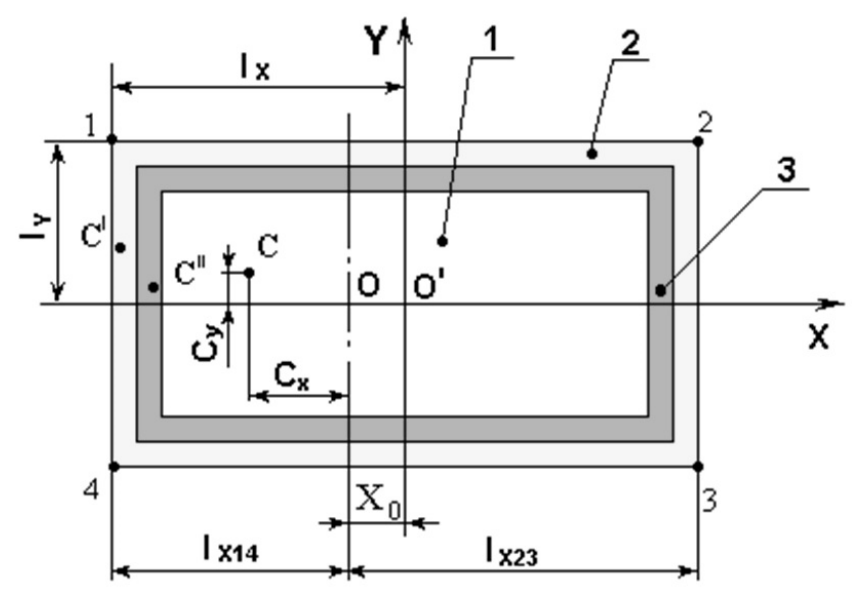

Fig. 2. Stability areas arrangement: 1: guaranteed stability;

2: dangerously low stability; 3 : check area

When $C_{X}<\left(l_{X}-0.6 l_{X}\right) / 0.6,\left(C_{Y}<\left(l_{Y}-0.6 l_{Y}\right) / 0.6\right)$, i.e. at $k<1.2$, the crane center of mass projection lies within the low stability area $2\left(C^{\prime}\right.$, Fig. 2$)$, and this is an emergency situation. There is a danger of crane tip-over. The proposed crane stabilization method has been developed to prevent it.

The method is as follows. When the center of mass displacement reaches the dangerously low stability area, all the drives are locked out and some hydraulic fluid is drained from the bottoms of the cylinders opposite to the tip-over edge. In this way, the base perimeter is shifted in the direction opposite to the load application direction, so the center of mass projection is carried over to the guaranteed stability area.

In order to avoid accidents, an extra area No. 3 (check area) has been introduced. According to the crane design and operation regulations, crane stability does not account for dynamic loads. Under static loads the stability factor $k \geq 1.4$.
In this way, the check area will lie within the following coordinate range:

$$
\begin{gathered}
\left(l_{X}-0.6 l_{X}\right) / 0.6<C_{X}<\left(l_{X}-0.7 l_{X}\right) / 0.7 \\
\left(l_{Y}-0.6 l_{Y}\right) / 0.6<C_{Y}<\left(l_{Y}-0.7 l_{Y}\right) / 0.7
\end{gathered}
$$

When the center of mass projection is in the check area (position $C^{\prime \prime}$ ), the current operation properties shall be changed (reduce the velocity, limit the boom length, reduce the motor torque) to prevent the center of mass shift to the dangerously low stability area.

So, the nolbilß exxne load1)tabilit(1)monitoring method includes periodic sensor polling in order to determine the center of mass projection relative to the base perimeter, detect the center of mass projection displacement direction towards the guaranteed stability area boundary, generating low stability alarms and drive commands.

The automated control system algorithm is as follows:

1. The outrigger load sensors send signals to the control system.

2. The current resultant fulcrum coordinates:

$$
x_{c}=\Sigma G_{i} x_{i} / \Sigma G_{i}, y_{c}=\Sigma G_{i} y_{i} / \Sigma G_{i}
$$

are determined.

3. The $\mathrm{C}$ point presence in the guaranteed stability area is checked.

4. The max load increment relative to the current value is estimated based on the stability safety margin.

5. A command for the crane drives is generated to maintain the safety margin above the threshold.

\section{HYDRAULIC OUTRIGGER PRESSURE MONITORING FOR STABILITY CONTROL}

The mobile crane stability control method uses pressure sensors in the outrigger pressure line. The method is as follows:

1. The load moment is estimated and compared to the limit value.

2. Based on the results, a command to the drives is generated to reduce the load moment.

3. Additionally, the outrigger hydraulic cylinder pressure variation rate and direction are detected.

4. Check pressure rate combinations are developed and compared to the reference values.

5. Depending of the match/mismatch of the control combinations a command is generated to change the crane properties that affect the stability.

Refer to Fig. 3 for the load moment estimation diagram.

A mobile crane stability control device includes a hydraulic line to the outriggers, a boom swing drive, an ADC, a CPU module. The CPU module memory stores a mathematical model of the mobile crane (customizable to match various load capacity.) There are pressure sensors in the outrigger hydraulic line. The CPU module is 
connected to the sensors, and the boom swing drive is a variable axial piston hydraulic motor.

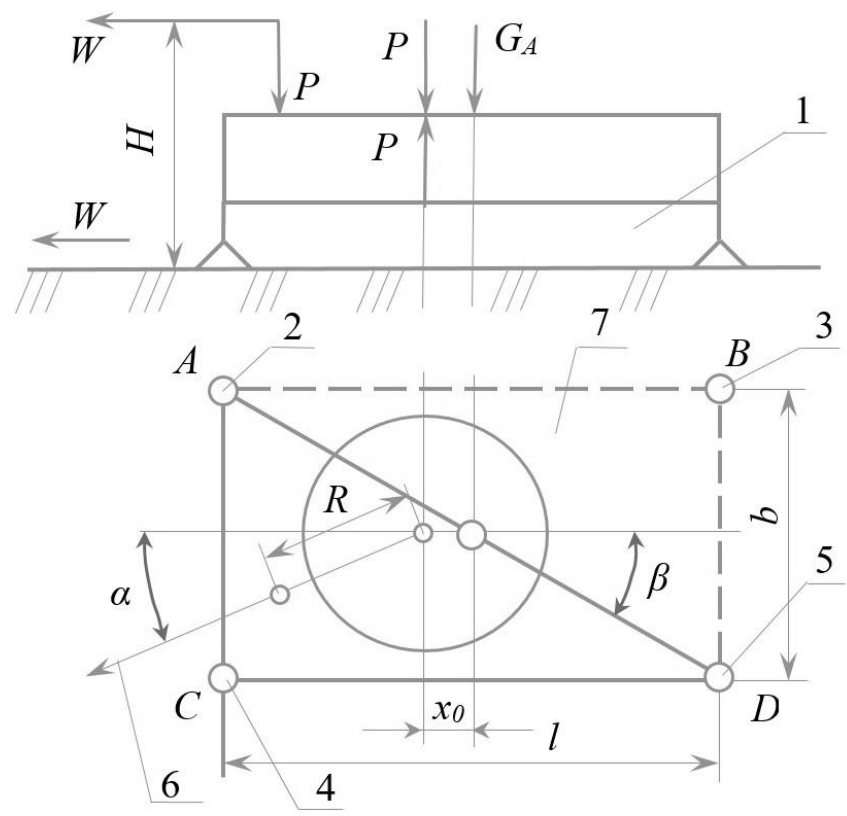

Fig. 3. Crane base plane diagram:

1: load diagram; $2,3,4,5$ : hydraulic outriggers carrying primary load; 6 : telescopic boom; 7: base perimeter

As the master hydraulic control valve is energized, the outrigger directional valves become operational and the crane is supported by the outriggers. The pressure sensors monitor pressure variation $P_{A}, P_{B}, P_{C}, P_{D}$ in the bottoms of the cylinders as the base perimeter 7 is transformed. The CPU module determines the pressure variation rate.

The diagram (Fig. 3) shows that at specified telescopic boom (Pos. 6) position, the three-point base perimeter (Pos. 7) bears most of the load. The perimeter vertices are the 2, 4, 5 hydraulic cylinders $(A, C, D)$ When the boom (Pos. 6) and load weight is translated to the swing drive center of rotation, a couple of forces is formed that generate an overturning moment.

The support loads are:

$$
\begin{gathered}
A=\frac{G_{\mathrm{H}}}{2}+\frac{P}{2}-M \cdot \frac{\sin \alpha}{b} \\
C=P \frac{x_{0}}{l}+M\left(\frac{\cos \alpha}{l}+\frac{\sin \alpha}{b}\right) \\
D=\frac{G_{\mathrm{H}}}{2}+\frac{P}{2}\left(1-\frac{2 x_{0}}{l}\right)-M \cdot \frac{\cos \alpha}{l}
\end{gathered}
$$

where $M=P \cdot R+W \cdot H$.
As a rule, a three-support base perimeter is used in hoisting operation modeling; the fourth support does not bear any loads in this case [12].

Since the crane truck chassis is suspended by raising pressure in the outrigger hydraulic cylinders, in normal operation the reference set of outrigger pressure variation rates as a load is lifted or moved relates to the boom position as:.

$$
\frac{\partial P_{A}}{\partial t}>0, \frac{\partial P_{C}}{\partial t}>0, \frac{\partial P_{D}}{\partial t}<0
$$

where $\frac{\partial P_{A}}{\partial t}, \frac{\partial P_{C}}{\partial t}, \frac{\partial P_{D}}{\partial t}$ are the pressure variation rates in the $A C D$ perimeter hydraulic cylinders. Such a set is reference data for a specified boom position relative to the supports.

The best way to implement online crane stability control is assessing the crane stability by checking the outrigger hydraulic pressure variation rates relative to the abovementioned base perimeter.

As the boom is swung, the load is shifted from one vertex (support) of the triangle base perimeter to another one, and the reference set now includes the pressure variation rate for the new base perimeter. At same time the follow-up system monitors the base frame horizontal position.

The system accumulates data in operation, and can forecast future value variations with a certain probability.

If the system detects that:

$$
\frac{\partial P_{A}}{\partial t}<0, \frac{\partial P_{C}}{\partial t}>0, \frac{\partial P_{D}}{\partial t}<0
$$

or

$$
\frac{\partial P_{A}}{\partial t}<0, \frac{\partial P_{C}}{\partial t}>0, \frac{\partial P_{D}}{\partial t}=0
$$

as a load is lifted of the boom is moved, it can be seen as a prerequisite for emergency situations. When there is the mobile crane tip-over danger, the system notifies the crane operator. If there is no operator intervention, the control system smoothly stops the swing and lock out any further movements in this direction. The operator has an opportunity to reduce the overturning moment and lower the load applied to the affected outrigger. To do so, one can reduce the boom extension, increase the boom slope angle (i.e. the distances between the crane center of gravity, the boom center of gravity, and the load center of gravity should be reduced). Such an intervention changes the loads applied to the outriggers.

\section{CONCLUSIONS}

Pressure sensors provide continuous crane stability monitoring. The sensor signals are fed to a ADC for conversion into a format convenient for processing. A CPU 
module processes the incoming information. The mod-ule consists of a CPU, a ROM, and a RAM chips.

The hydraulic boom swing drive (a variable axial pis-ton hydraulic motor is to be installed) and the outrigger hydraulic circuit (pressure sensors are to be installed) retrofitting efforts are low.

The stability control method is versatile and future-proof since it uses a flexible mathematical model stored in the onboard computer memory. The model can be changed or made more complex to match a specific crane design features (e.g., including more monitored variables, introducing new control methods, etc.) as the regulations become more stringent and more crane de-velopment/hoisting machinery safety research is carried out. During the research three patents were received [27-28].

\section{Acknowledgment}

The results of the research project are published with the financial support of Tula State University within the framework of research project No. 2017-31.

\section{References}

[1] G. Kunze, Mobile "Construction Machines Developments and Main Areas of Research”. ATZoffhighway. Vol. 6(1), 2013. pp. 4-16.

[2] Z. Struková and M. Ištvánik, "Tools for mobile crane selecting and locating", International Review of Applied Sciences and Engineering, Vol. 2(1), 2011, 69-74.

[3] A. Maczynski and S. Wojciech, "Dynamics of a mobile crane and optimisation of the slewing motion of its upper structure", Nonlinear Dynamics, Vol. 32 (3), 2003, pp. 259-290.

[4] K. Tantisevi, A Burcu, "Automated generation of workspace requirements of mobile crane operations to support conflict detection", Automation in Construction, Vol. 16(3), 2007, pp. 262-276.

[5] M. Majewski, W. Kacalak, Z. Budniak, M. Pajor, "Interactive control systems for mobile cranes", Proceedings of the Computational Methods in Systems and Software, 2017, pp. 10-19.

[6] J. Y. Chew, K. Ohtomi H. Suzuki "Skill Metrics for Mobile Crane Operators Based on Gaze Fixation Pattern", Advances in Human Aspects of Transportation, book series (AISC, volume 484), First Online: 07 July 2016, pp 1139-1149.

[7] Q. Dong, G. Xu and H. Ren, "Risk assessment of remanu-facturing arm structure for crane based on potential failure mode", Journal of Mechanical Science and Technology, Vol. 29 (12), 2015, pp. 53455357.

[8] S. Tamate, S. Naoaki and K. Toshiyuki, "Analyses of instability in mobile cranes due to ground penetration by outrigger", Journal of Construction Engineering and Management, Vol. 131(6), 2005, pp. 689-704.

[9] K. Song, Y. Xue, L. Xu, B. Zhang. "Research on the overload protection system of knuckle boom crane", Proceedings of China Modern Logistics Engineering, Part of the Lecture Notes in Electrical Engineering book series, LNEE, Vol. 286, 2014, pp. 189-197.

[10] M.I. Zatravkin, L.S. Kaminskij et all, "Method of and Device to Control Load-Lifting Crane", Patent RU 2309112 of 27.10.2007, Federal Service for Intellectual Property, Patents and Trademarks, Moscow, 2007.
[11] V.A. Korovin and K.V. Korovin, "Hoisting or Construction Machine Load Limiter", Patent RU 2448037 of 20.04.2012, Federal Service for Intellectual Property, Patents and Trademarks, Moscow, 2012.

[12] J.B. Tikhonov, "Lifting Crane Control Method and System for its Implementation", Patent RU 2457170 of 27.07.2012, Federal Service for Intellectual Property, Patents and Trademarks, Moscow, 2012.

[13] N.Q. Hoang, S-G Lee, H. Kim and S.-Ch. Moon, "Trajectory planning for overhead crane by trolley acceleration shaping", Journal of Mechanical Science and Technology, Vol. 28 (7), 2014, pp. 2879-2888.

[14] H. Safouhi, M. Mouattaid, U. Hermann and A. Hendi. "An algorithm for the calculation of feasible mobile crane position areas", Autom Constr, Vol. 20(4), 2011, pp. 360-367.

[15] T. Miyoshi, S. Kawakami and K. Terashima, "Path Planning and Obstacle Avoidance Considering Rotary Motion of Load for Overhead Cranes", Journal of mechanical systems for transportation and logistics, vol. 1, 2008, pp. 134-145.

[16] K. Tantisevi and B. Akinci. "Automated generation of workspace requirements of mobile crane operations to support conflict detection", Autom Constr, 16(3):262-276 (May 2007)

[17] C. Zhang and A. Hammad, "Improving lifting motion planning and replanning of cranes with consideration for safety and efficiency". Adv Eng Inform 26(2):396-410 (Apr 2012)

[18] V.Y. Antsev, A.S. Tolokonnikov, A.D. Gorynin and A.A. Reutov, "A statistical model of operational impacts on the framework of the bridge crane", IOP Conference Series: Materials Science and Engineering, vol. 10, 2017, pp. 012053.

[19] J. Olearczyk, A. Bouferguène, M. Al-Hussein et al. "Automating motion trajectory of crane-lifted loads", Automation in Construction, Vol.45, 2014, pp. 178.

[20] C. Vázquez, S. Aranovskiy and L.B. Freidovich, "Input nonlinearity compensation and chattering reduction in a mobile hydraulic forestry crane", Elektrotechnik und Informationstechnik, Vol. 133 (6), 2016, pp. 248-252.

[21] Z. Lei, H. Taghaddos, U. Hermann 'A methodology for mobile crane lift path checking in heavy industrial projects", Autom Constr, Vol. 31, 2013, pp. 201341-53.

[22] J. Olearczyk, Z. Lei, B. Ofrim, Sh. Han and M. Al-Hussein, "Intelligent Crane Management Algorithm for Construction Operation". In: 2015 Proceeding of 32nd ISARC

[23] L. S. AbbottEmail, Le Peng and David K. H. Chua, "Using Building Information Modelling to Facilitate Decision Making for a Mobile Crane Lifting Plan", EPPM 2017: 8th International Conference on Engineering, Project, and Product Management (EPPM 2017), pp 77-89.

[24] M. R. AlamS. F. Hassan, M. A. AminK. Arif-Uz-ZamanM. A. Karim, "Failure Analysis of a Mobile Crane: A Case Study" Journal of Failure Analysis and Prevention, 22 March 2018, pp 1-9.

[25] J. Kłosiński and J. Janusz, "Control of operational motions of a mobile crane under a threat of loss of stability", Solid State Phenom. Vol. 144 2009, pp. 77-82.

[26] B. Grigorov and R. Mitrev, Dynamic behavior of a hydraulic crane operating a freely suspended payload, Journal of Zhejiang University, vol. 18(4), 2017, pp. 268-281.

[27] P.A. Sorokin, A.V. Red'kin and M.V. Kozlov, "System for Checking Load Stability of Mobile Load-Lifting Machine“, Patent RU 2267458 of 1.10.2006, Federal Service for Intellectual Property, Patents and Trademarks, Moscow, 2006.

[28] A.V. Chernov, A.V. Red'kin and P.A Sorokin, Method of Crane Operation Control, Patent RU 2440924 of 4.20.2012, Federal Service for Intellectual Property, Patents and Trademarks, Moscow, 2012. 